\title{
Teaching Peculiarities of Guohua Painting Basics to Non-Chinese Students
}

\author{
Julia Naumova \\ Post-graduate of drawing and graphics department \\ Culture and Arts Institute \\ Moscow City Pedagogical University \\ Moscow, Russia
}

\begin{abstract}
The article is devoted to the teaching of Chinese painting to non-Chinese students of different age groups. Methodological possibilities of Chinese painting as an alternative means of visual skills and creative abilities are also shown in the article.
\end{abstract}

Keywords-chinese painting; guohua techniques; aesthetic development; creative work; tradition of painting

\section{INTRODUCION}

Teaching of art is of one of the most effective developing methods of creative abilities. One of the most important keys of the creative and aesthetic development is the relationship of art and creative activity of a student and development of expressive features of different types of art, especially which are not "familiar" in his environment. Many sources recommend starting to learn the fine arts since childhood, but more and more people of different ages think about the benefits of painting classes in personal terms. Popular belief that studying art in practice is a privilege of those who have a pronounced ability to draw, just out of date.

In the 21 st century, China and Russia gained great cooperation. We can say that after 66 years Russian-Chinese relations are currently one of the most stable and mature between the two countries in the world.

Over the past few decades, thanks to cooperation with Russia in the field of professional art education, a system of professional artists' training has developed in China, which is based on the traditions of Russian academic school of painting and drawing.

Unfortunately, in Russia many areas of knowledge relating to the cultural artistic traditions of China, until recently, were a study area of Oriental scholars. Despite the excellent works of the famous Russian experts in the field of Oriental Studies, such as Malyavin V.V., Vinogradova T.I., Zavadskaja E.V., Belozerova V.G. etc. on Chinese culture and arts, the issue of traditional Chinese painting tradition as an alternative method of visual skills, creativity and aesthetic perception, practically was not discussed seriously for a long time.

In the last decade, thanks to technology development in the field of informational technology, an integration of different cultures and nations is going on, cultural traditions of a country such as China have become closer, more and more people have the opportunity, in addition to Chinese language, to learn, to understand and master a variety of traditional Chinese arts as such as wushu, tea ceremony, Paper Cuttings (jianzhi 剪纸), traditional Chinese carving seals (zhuanke 管刻), calligraphy (shufa 书法), Chinese painting (Guohua 国画) etc.

At the moment, the lessons directly related to the study of Chinese art, exist only in general educational program of schools in the form of a very short course of lectures, giving a superficial idea about the features of Chinese art in general and Chinese painting Guohua in particular. There are attempts to unite theory and practice, but they are very originally presented by teachers and are short of theoretical and practical base, let alone the procedure. The problem of implementation of such programs in the process of teaching art in schools, colleges and universities in Russia, as well as in additional education systems, it is directly related to the lack of trained professionals in the field of teaching of Chinese painting.

Summarizing mentioned above, we can come to a conclusion about the necessity of a universal method's creation that promotes learning traditional Chinese painting Guohua in the face of strong interaction of artistic traditions of China and Russia, which can be used as a teaching tool for practicing aesthetic and artistic cycle, as a means of expanding horizons of Art faculties students of secondary and higher educational institutions, as well as on the training courses of teachers of the fine arts.

\section{The Method OF GUOHUA PAINTING'S TEACHING FOR NON-CHINESE STUDENTS}

The methods of Chinese painting's teaching developed by the author is fundamentally different from traditional Western methods of education, also contributes to the development of creative abilities of children and adults who have not previously trained artistic literacy, as well as a common methodology.

This methodology was developed based on the Chinese system of knowledge about the world, the experience of Chinese teachers of Guohua, the achievements of Chinese 
scientists in the field of philosophy and pedagogy, as well as the author's many years of experience in teaching Chinese painting Guohua. This has allowed to adapt the learning process directly to Russian standards. The curriculum, which is the basis of this methodology, has a block system tasks.

The learning process is based on the principle of gradual transition from the academic style "Gunbi" to the freer style of "Se-e."

Each block has a compulsory practical exercises, without which the development of Chinese painting techniques will be imperfect. The program is for 2 years, lesson is once a week. Such hours distribution is due to the peculiarity of the Russian fine art learning system, when in a week there are all objects of artistic cycle in the schedule of activities of art schools and colleges, such as: painting, drawing, sculpture, composition have their part time in the schedule grid in one week, so the students study these subjects during the entire period of their study in an educational institution.

This timetable of Guohua is also suitable for additional education, such as art schools, art studio and leisure centers, and others.

Each block of the curriculum is divided into sections: prologue - the development of technique, the main partimplementation of simple compositions, copying of classical models, and the final part - creation of the final work in an appropriate style.

Distribution of blocks in such order-flowers and birds in a contour technique Gunbi, flowers and birds in noncontour technique mogufa, flowers, birds and animals in free Se-e technique, landscape - is stipulated by the fact that each style or genre of Chinese painting has its technical base and stylistic peculiarities.

The method of copying is illustrative for Gunbi style, which is a good basis for the development of initial skills of flowers and birds painting, and contour method is perfect for exploring the rules of brush, accustom to accuracy, develops the ability to control thickness of lines, learn to analyze the tone and color gradation of mineral paints and China ink.

And "rice" paper shusyuan (shuxuan 熟宣), which is used for paintings in Gunbi style remains paper for watercolor painting or drawing with its characteristics - it does not get wet, keeps water, multi-layered, transparent technique and special effects are possible on it. That is why the first block is devoted to Gungbi. Practice and interviews with Russian students' of different levels in the field of Fine Arts shows, Gungbi style is more easily accepted than the style of Se-e both practically and theoretically.

During the first semester, which consists of 20 lessons, students perform on paper and silk copies of famous works of the Song Dynasty in the following order: "Hibiscus, came out of the water» (出水芙蓉图), «Mountain flower and butterfly»(山花蝴蝶图), "Bird and ripe fruit»(果熟来禽图), «Plum, bamboo and a frozen bird» (梅竹寒禽图), «Loquat and white eye»(枇杷绣眼图). Gradebook work-"Basket with flowers» (花蓝图).
The second block is also consists of 20 lessons and introduces students to the method of applying color in noncontour method "Gunba mogufa» (工笔没骨法), forming knowledge about the integrity of the composition. This method introduces a choice of color solutions of the future picture, a reasonable knowledge of the laws of traditional Chinese color perception. Training goal is to copy Yun Shoupina (恽寿平) and $\mathrm{Ni}$ Yun (倪耘) as well as contemporary authors such as 贾广健, 周午生, 张瀚文 and others. It should be noted that this method is very popular because it has little resemblance to the watercolor technique, familiar to Russian students since childhood. During this block students are also getting familiar with the laws of the Chinese compositions with sketching and methods of use of full-scale material to create their own compositions. It may be noted that despite the fact that many students without any skills, thanks to Gunbi lessons in the first block, almost all cope with pencil sketches from nature (flowers, plants, household items, etc.).

Knowledge of peculiarities of the Chinese composition enables students to compose independently items previously shown, to make the finishing circuit, and placing it under the rice paper or silk, to perform the fill color, thus ending their own picture.

The third block of 20 lessons is devoted to a detailed study of Se-e style which is the largest part of all task provided by a pilot program. Its main task is teaching of other means of painting, different from those that were in the first two blocks (more absorbent paper, brushes with different composition and size). At this stage students are acquainted with a variety of techniques and methods of work of free style of Chinese painting, which is based on drawing on paper the exact spots and strokes without prior sketching pencil, students acquire the necessary skills of whole perception of objects and image analysis.

As it turned out in the learning process, the most difficult for Russian students is paper shensyuan (shengxuan 生宣), because it, unlike paper shusyuan for Gunbi, absorbs ink. Therefore, the first lesson is entirely devoted to the control of water and set of Chinese ink on the brush. Particular attention is paid to the brush position zhongfeng (中锋) and cefeng (侧锋), and techniques such as the sumo (宿墨), pomo (泼墨), zimo (积墨).

It should be noted that usage of visual learning method is necessary for Russian students during the process of Chinese painting training, in addition to theoretical basis. In China usually children are taught in this way-teacher draws, children repeat. Taking into consideration that Chinese students at an early age absorb traditional culture, which includes philosophy, writing, visual and other arts, Chinese painting learning process at higher education is based on previously obtained knowledge by students. Therefore, demonstration brush technique by teacher takes less time than the same classes in Russia. Normally, demonstration takes up $30 \%$ to $50 \%$ of the lesson. 
Only when students understand the principle of applying Chinese ink on paper, one can start copying from the samples and the implementation of independent work.

The samples used to copy are the paintings of famous artists Zhu Da, Du Dacheng, Jin Nong, Wu Changshu, Qi Baishi. In the end, there is control work. Students themselves choose the subject for the final paintings, as well as the technique (color or monochrome).

In all three blocks in the development of tasks subject compositions of genre "bird flowers" (Hua Nyao) was used. This genre is traditionally considered to be easily grasped by beginners, subjects are related to the plant picture, flowers and birds. But also here, Russian students are faced with the problem, which usually do not face Chinese students. Many of the depicted plants and flowers grow exclusively in China and the southern countries, such as bamboo, hibiscus, lotus and others. Russian students are difficult to imagine how to grow or even look one or another plant, flower or tree. Despite the fact that the program includes visits to the Botanical Garden, where students can take photographs and make sketches from nature of various exotic plants, and documentary films about nature of China, it is not entirely compensate for the lack of visual material.

The fourth and final block is devoted to one of the most difficult genres of Chinese painting - Landscape (Shan Shui). The author, based on the personal teaching experience, consciously put landscape in the final part of the curriculum.

Since the Chinese landscape is a leading genre of Chinese painting and the most difficult to master even by Chinese students, for Russian students the task is more complicated by the lack of full-scale material, the inability to see those natural objects that inspired Chinese artists for millennia.

Therefore, in addition to the development of landscape art technique, visiting of photo exhibitions devoted to China, as well as two or three-week study trips in Chinese universities in Hunan and Henan, where Russian students are organized field trips, excursions to the landscape areas, are included to this block.

Such three-week trips were made in 2014, 2015 and 2016 and caused great interest among the participants to lessons, nature, flora and fauna of China, as well as home, Chinese cuisine, habits and way of life of ordinary people. The classes consisted of mandatory classes of Chinese calligraphy, where participants acquainted with the styles, techniques and history of Chinese writing. Then there were lessons in painting - a genre of flowers, birds and scenery. One trip was organized specially for beginners and included lessons on Gunbi and Xiao Se-e. After the return all the participants showed interest in further study of Chinese painting, and also to the development of calligraphy, Chinese language, engraving seals.

\section{CONCLUSION}

As conclusion, it must be mentioned, that due to cultural relations between our two countries and Internet, the availability of information about cultural traditions of other countries has enabled Russian people to appreciate originality and significance of Chinese art in the world culture. This possibility let people learn the art of China, not only in books but also in practice. The complexity of Chinese art mental perception by Russian students may be overcome with the system of trainings that takes into account all differences of Chinese and Russian educational space.

Due to transfusion of two great cultures multicultural space may arise, in which Chinese painting, as an alternative method of fine arts teaching, will enrich and fill up the existing Russian system of art education

Being bright and original, Chinese painting Guohua is an excellent tool for creating of fine perception of the world and nature, which gives a beginner to develop artistic skills, and professional artists to receive a range of additional opportunities for self-expression.

\section{REFERENCES}

[1] Rostovtsev H.H. Development of creative abilities at drawing lessons: Study guide. M .: Education, 1987.

[2] Roshin S.P. About motivation on art skills mastering during training of artist-teacher // Ways and means to improve the quality of art education and aesthetic perception / Ed. V.V. Koreshkov. M. Moscow State Pedagogical University, 2012.

[3] Li Dongxu. "Chinese landscape painting for beginners": Beijing, Foreign Languages Press, 2006.

[4] Wu Yanmu. Introduction to the techniques of Chinese painting. Shanghai, 1985. 